\title{
Gender Differences in the Relationship between Type 2 Diabetes Mellitus and Employment: Evidence from the Korea Health Panel Study
}

\author{
Jeung-Hee Kim ${ }^{1,2}$, Weon-Young Lee ${ }^{3, *}$, , Song Soo Lim ${ }^{2, *}$, , Young Taek Kim ${ }^{4}$ and \\ Yeon-Pyo Hong ${ }^{3}$ \\ 1 Division of Chronic Disease Control, Korea Disease Control and Prevention Agency, \\ 187 Osongsaengmyeong 2-ro, Osong-eup, Heungdeok-gu, Cheongju-si, Chungcheongbuk-do 28159, Korea; \\ 1sgirl@hanmail.net \\ 2 Department of Food and Resource Economics, College of Life Science and Biotechnology, Korea University \\ Graduate School, 145 Anamro, Seongbuk-gu, Seoul 02841, Korea \\ 3 Department of Preventive Medicine, College of Medicine, Chung-Ang University, 84 Heukseok-ro, \\ Dongjak-gu, Seoul 06974, Korea; hyp026@cau.ac.kr \\ 4 Public Health Medical Service Office, Chungnam National University Hospital, 282 Munhwa-ro, \\ Jung-gu, Daejeon 35015, Korea; ruyoung01@gmail.com \\ * Correspondence: wylee@cau.ac.kr (W.-Y.L.); songsoo@korea.ac.kr (S.S.L.)
}

Received: 8 September 2020; Accepted: 24 September 2020; Published: 26 September 2020

\begin{abstract}
Previous studies have analyzed the impact of diabetes mellitus on labor market participation by men and women, but gender difference between type 2 diabetes mellitus (T2DM) and employment has not been the focus. This study aims to explore gender differences between T2DM and employment status. Data from the Korea Health Panel Study, 2013-2015 were analyzed by distinguishingT2DM and non-diabetes $(N=11,216)$. The empirical model was established and the generalized two-stage least squares (2SLS) was estimated, controlling for endogeneity. A family history of diabetes, as an instrumental variable, was related to an individual's genetic predisposition to develop diabetes. The estimated results for the 2SLS showed the interaction effects between T2DM and employment. T2DM had a statistically significant and negative effect on employment for women only. The comparison with non-diabetes showed that women with T2DM had a lower probability of employment by $51.9 \%(p<0.05)$. Exposing gender bias in employment suggests that healthcare policies and disease management programs for diabetic patients should adopt gender-specific remedies.
\end{abstract}

Keywords: gender difference; type 2 diabetes mellitus; employment; Korea

\section{Introduction}

Diabetes mellitus is a global health problem. The World Health Organization (WHO) estimated that 422 million adults were living with diabetes in 2014 as compared with 108 million in 1980 . The global prevalence of diabetes in individuals aged $>18$ years has nearly doubled since 1980, increasing from $4.7 \%$ to $8.5 \%$. Over the past decade, diabetes prevalence has more rapidly increased in low- and middle-income countries than in high-income countries [1]. The Centers for Disease Control and Prevention estimated that 23.1 million adults aged $\geq 18$ years have diabetes, accounting for $7.2 \%$ of the U.S. population. The impact of the direct and indirect costs of diabetes on the national economy is shown by losses in gross domestic product(GDP) worldwide from 2011 to 2030, which amounts to USD 1.7 trillion [2]. The burden of diabetes in Korea is more problematic than in any other part of the world. Diabetes ranked fifth among the major causes of death in 2007 and sixth in 2017 [3]. According to the Korea National Health and Nutrition Examination Survey in 2017, the prevalence of diabetes in 
individuals aged $\geq 30$ years was $10.4 \%$. In terms of gender, the prevalence of diabetes in men $(12.4 \%)$ was higher than that in women (8.4\%) [4]. Furthermore, $90 \%$ to95\% of all diabetes cases are likely to be type 2 diabetes mellitus (hereafter T2DM) [5]. The prevalence of T2DM has shown a rapid increase from $<1 \%$ in 1960 to $6-9 \%$ by the end of the 1990s, and has been related to rapid urbanization, which introduced Western diet, lower levels of physical activity, and an increasingly obese population [6].

Relatively fewer studies have focused on the gender differences between T2DM and employment. Previous studies have analyzed the impact of diabetes mellitus on labor market participation by men and women [7]. Researches in Australia, Canada, and a number of European countries have examined the negative impact of diabetes on labor market participation outcomes [8-10]. In Australia, people with diabetes have a lower probability of being in the labor force for all age groups, and those out of the labor force have access to substantially lower incomes in retirement than non-diabetic people. In Canada, diabetic individuals with complications are twice as likely not to be in the labor force than their non-diabetics counterparts. In Europe, people diagnosed with diabetes have a $30 \%$ increase in the rate of labor force exit as compared with those without diabetes. These samples include women and men who are either randomly or consecutively selected as respondents.

Gendered inequalities vary with respect to employment and working conditions, with differences seen in occupations and economic activities, contract types, wages, access to labor rights and benefits, and working times $[11,12]$ which can have beneficial or damaging effects on health. As indicated by the $\mathrm{WHO}$, the unequal distribution of working conditions is a key contributor to social inequalities in health. Equal job opportunities for women and men and equal payment for the same job are still rarely seen around the world. In particular, women's health inequalities have been related to an unequal distribution of social and family roles [13,14]. Gender roles play an important part in individuals' roles, such that men rate their career role as more important than their family role as compared with women. Furthermore, sizeable gender gaps in employment and wages remain in virtually all countries, and women are underrepresented in high-paying occupations and leadership positions. In the USA, women earn, on average, $20 \%$ less than men on an hourly basis, and their employment rate is about 10 percentage points lower than that of men [15]. In the case of Korea, women continue to comprise a much greater proportion of the labor for rearing children, serving as the communication hub for family members, and managing family health. For this reason, women may be more vulnerable to stress both at home and in the workplace than men [16].

Therefore, this study examined the relationship between T2DM and employment status in terms of gender differences. To assess the causal relationships, we used the Korea Health Panel Study, an ongoing longitudinal study conducted in 2013-2015. We estimated the generalized two-stage least squares (2SLS), controlling for endogeneity. Family history of diabetes, as an instrumental variable (IV), was related to an individual's genetic predisposition to develop diabetes [17-19].

\section{Materials and Methods}

\subsection{Data Source}

The Korea Health Panel Study (KHPS Version 1.4) is an official statistical investigation that has been conducted annually since 2008 by the Korea Institute for Health and Social Affairs and National Health Insurance Service. In selecting respondents nationwide, the KHPS uses stratified multistage probability sampling according to region and residence from the 2005 Korea Census. The objectives of the investigation were to identify the factors influencing the use of health care services, health expenditures, and financial resources, and to provide basic information on policy implementation by continuing to observe health care trends. The data collected were on demographic socioeconomic characteristics (e.g., age, sex, marital status, education level, health insurance type, employment status, household generation, and household income), chronic illness, and medical use, including medication, emergency service, and admission, of 7000-8000 household members who agreed to complete in-home face-to-face interviews in 16 cities/provinces [20]. 
To examine the association between T2DM and employment decisions, we used data from 5521 households and 16,247 individuals in 2013, 5284 households and 15,263 individuals in 2014, and 5098 households and 14,344 individuals in 2015.

\subsection{Study Design}

The key dependent variable of the KHPS was the change in employment status of an individual who was employed in 2013, as indicated in Figure 1. In two consecutive years, respondents participated in a household survey, which was classified by household code. We identified 10,467 consecutive households with the parameters assessed, including presence of chronic illness, employment, and household income. In econometrics analysis, the structure of panel data should be changed from wide to long type [21]. Thus, our dataset reshaped the structure of the data and contained a balanced panel without annual time gaps. Among 33,423 household respondents, the sample was restricted to those of working age at $30-55$ years, with the average age being 46 years. The final sample size was determined as 11,216 household respondents.

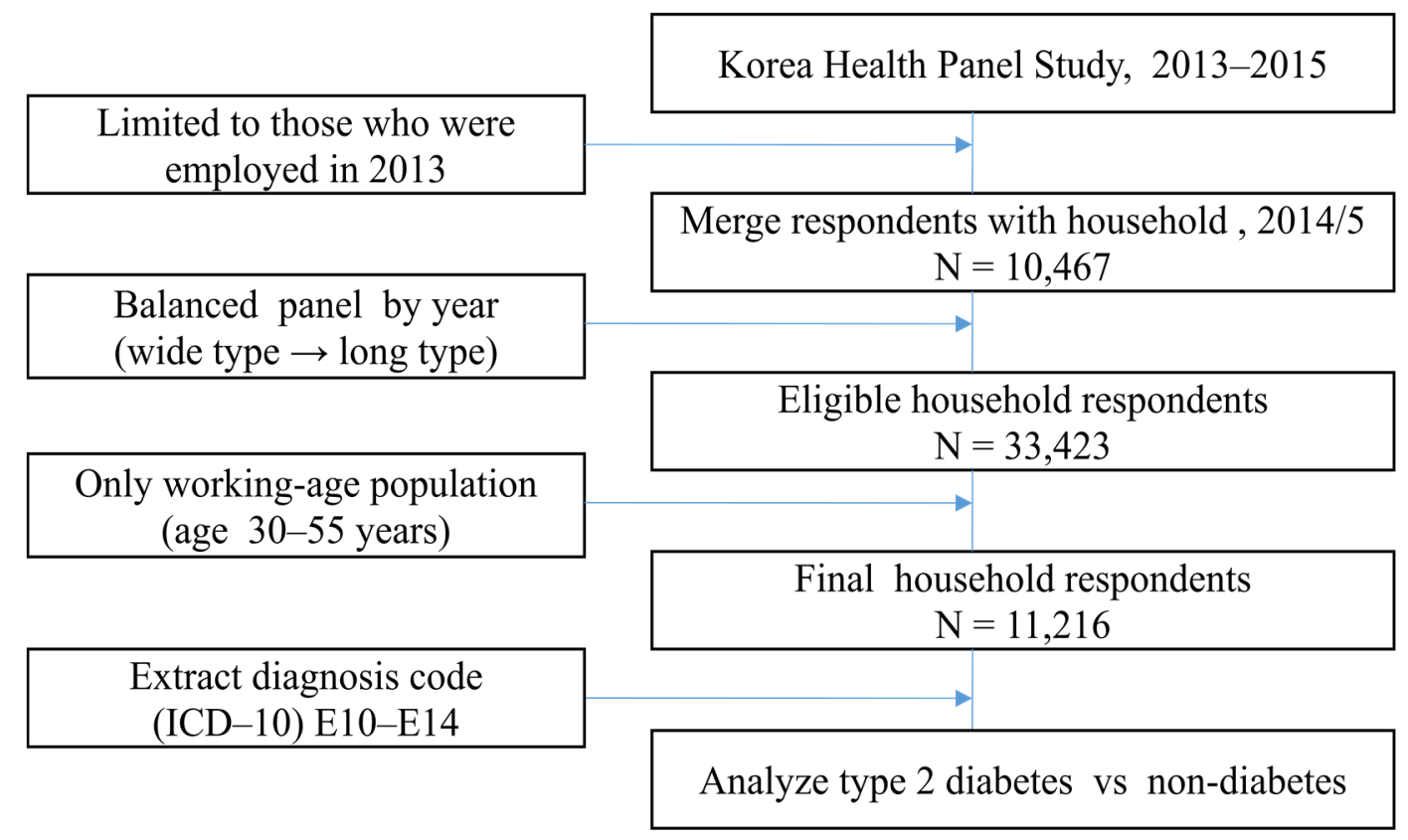

Figure 1. Study design.

\subsection{Variable Selection}

Longitudinal studies considered the International Classification of Diseases10 (ICD-10) of survey participants when indicating the type of chronic disease. We extracted respondents who met the ICD-10 code for diabetes diagnosis, E10-E14, from the KHPS data. Specifically, to avoid obtaining biased estimates of the effects of diabetes on labor market outcomes, we distinguished between T2DM and non-diabetes cases. Hence, respondents with missing values of the chronic disease code and those who were diagnosed without consideration for the combination of co-morbidities (e.g., hypertension, hyperlipidaemia, arthropathy, and ischemic heart disease), which could lead to bias in estimates attributable to diabetes, were excluded.

The employment variable was obtained from a question that asked if the individuals were working for 12 months before the interview. Sociodemographic variables included age, marital status, education, school graduation, and national health insurance. Education variables were characterized as no formal education, elementary school, middle-high school, 2-4 years of college, or graduate school. Because Korea has adopted universal insurance coverage since 1989, national health insurance variables have been classified into two types, which are consistent with the characteristics of employment 
status and medical aids [22]. The household region variable included respondents who lived in 16 cities/provinces that were categorized as urban or rural regions. Household generation was defined as the number of generations in a household, consisting of the first generation, second generation, and so on. Household head indicated whether the individual was the householder or the head of a family. The owner of the house variable indicated whether or not the individual owned the house. Yearly household income (KRW10,000) was the total income of all household individuals who lived in a house. Subjective health satisfaction variables were categorized as normal-good or bad [23,24]. The variable definitions are given in Table 1.

Table 1. Definition of variables.

\begin{tabular}{|c|c|c|}
\hline Variable & Variable Name & Definition \\
\hline Employment status & Employment & $\begin{array}{l}1 \text { if employed in each year from2013to2015; } \\
\qquad 0 \text { otherwise }\end{array}$ \\
\hline Diabetes mellitus & T2DM & $\begin{array}{l}1 \text { if diagnosed with diabetes code E10-E14; } \\
0 \text { if non-diabetic }\end{array}$ \\
\hline Family history of diabetes & Sibling diabetes & $\begin{array}{c}1 \text { if sibling with diabetes; } \\
0 \text { otherwise }\end{array}$ \\
\hline \multirow[t]{4}{*}{ Sociodemographic } & $\begin{array}{c}\text { Age } \\
\text { Marital status }\end{array}$ & $\begin{array}{l}1 \text { if } 30-39 \text { years; } 2 \text { if } 40-49 \text { years; } 3 \text { if } 50-55 \text { years } \\
1 \text { if married; } 0 \text { if divorced/widowed/separated }\end{array}$ \\
\hline & Education & $\begin{array}{l}1 \text { it no formal education; } 2 \text { it elementary school; } \\
3 \text { if middle-high school; } 4 \text { if } 2-4 \text { years of college; } \\
5 \text { if graduate school }\end{array}$ \\
\hline & School graduation & 1 if yes; 0 otherwise \\
\hline & National health insurance & 1 if health insurance; 0 if medical aids \\
\hline \multirow[t]{5}{*}{ Households } & Household region & $\begin{array}{l}1 \text { if area of residence is urban; } \\
0 \text { if area of residence is rural }\end{array}$ \\
\hline & Household generation & $\begin{array}{l}\text { number of generations: first generation, } \\
\text { secondgeneration, etc. }\end{array}$ \\
\hline & Household head & 1 if yes; 0 otherwise \\
\hline & Owner of the house & 1 if house ownership; 0 otherwise \\
\hline & yearly household income & $\begin{array}{l}\text { the total income of all household ones } \\
\text { (in KRW10,000) }\end{array}$ \\
\hline \multicolumn{2}{|c|}{ Subjective health satisfaction } & 1 if normal-good; 0 if bad \\
\hline
\end{tabular}

We used family history of diabetes as an IV, which would explain the association between T2DM and employment outcomes as a potentially endogenous variable in the analyses. Employment participation could influence unmeasured personal characteristics, such as age at diabetes onset, Westernized diet, and exercise. Personal traits could influence employment; motivation could influence lifestyle choice; and healthy lifestyles could decrease the risk of developing diabetes $[25,26]$. Thus, unobserved factors need to be controlled for because T2DM could lead to endogeneity bias with respect to employment status. Our study used the sibling with diabetes variable as an IV extracted from the KHPS data (e.g., diabetic grandparent, diabetic parents, and diabetic sibling), to control for unobserved factors of T2DM.

\subsection{Empirical Model}

To analyze the characteristics of the panel data, we tested the study hypotheses using the Hausman test for fixed effects (correlated errors) vs. random effects. The null hypothesis was not rejected because the $p$-value was 1.000 in men but 0.392 in women. Therefore, the preferable model was the random effects model at the $5 \%$ level of confidence [21]. Two models were subsequently estimated. Model I assumed that estimates of T2DM were exogenous and indicated the average effect of T2DM relative to those without diabetes. Model II was estimated with the generalized two-stage least squares (2SLS) using a diabetic sibling as an IV [27]. Thus, we used Model I for probit regression and Model II for2SLS regression.

Model I:

$$
\mathrm{Y}_{i t}^{*}=a+\beta_{1} \mathrm{X}_{i t}+\beta_{2} \text { Type }_{i t}+u_{i}+e_{i t}
$$




$$
\left\{\begin{array}{c}
\mathrm{Y}_{i t}=1 \text { If } \mathrm{Y}_{i t^{*}}>0 \\
\mathrm{Y}_{i t}=0 \text { Otherwise if } \mathrm{Y}_{i t^{*}} \leq 0, u_{i} \sim N\left(0, \sigma_{\mathrm{u}^{2}}\right)
\end{array}\right.
$$

where $Y_{i t}{ }^{*}>0$ and $Y_{i t}{ }^{*} \leq 0$ represent that individual $i$ is employed or otherwise, respectively. The variable $Y_{i t}$ is dichotomous, which is equal to 1 if individual $i$ employed during the survey period. $X_{i t}$ is a vector of sociodemographic (age, marital status, education, school graduation, and national health insurance), household variables (household region, household generation, household head, owner of the house, and yearly household income) and subjective health satisfaction variables. Type $2_{i t}$ is an indicator variable, which is equal to 1 if individual $i$ has reported a diagnosis of T2DM and 0 if otherwise. Moreover, $\mathrm{u}_{i}$ is a stochastic error term.

Model II:

$$
\begin{gathered}
\text { Type } 2_{i t}=\delta_{1}+\delta_{2} \mathrm{X}_{i t}+\delta_{3} \mathrm{Z}_{i t}+v_{i}+\varepsilon_{i t} \\
\mathrm{Y}_{i t}=a+\beta_{1} \mathrm{X}_{i t}+\beta_{2} \hat{\mathrm{T} y p e} 2_{i t}+u_{i}+e_{i t}
\end{gathered}
$$

Type $2_{i t}$ is dichotomous, which is equal to 1 if individual $i$ has reported a diagnosis of T2DM and 0 if otherwise during the survey period. $X_{i t}$ is a vector of sociodemographic (age, marital status, education, school graduation, and national health insurance), household variables (household region, household generation, household head, owner of the house, and yearly household income), and subjective health satisfaction variables. $Z_{i t}$ is a vector of family history of diabetes as an IV. The model assumes that $u_{i}$ is normally distributed. Particularly, the assumption of $\operatorname{Cov}\left(\mathrm{X}_{i t}, u_{i}\right)=0$ is needed for a 2SLS estimator to satisfy a consistent estimator. For ameliorating the endogeneity bias, the second equations were calculated estimates of T2DM (T्ype $2_{i t}$ ) using the IV, such as sibling with diabetes.

\section{Results}

Our final sample size was 11,216, comprising 5466 men and 5750 women. Table 2 shows the descriptive statistics by gender with and without T2DM. The sociodemographic characteristics of household respondents who were employed in 2013 included the changes in employment status and working conditions in 2014-2015. Considering the population with T2DM in the two consecutive years, we found that $94.2 \%$ of men were employed as compared with $77.9 \%$ of women.

In men, the average age of individuals with T2DM was 46.6 years, and that of those without diabetes was 45.6 years. The T2DM group marked a relatively higher proportion of older respondents $(p<0.05)$ and those living in multigenerational households $(p<0.01)$ as compared with non-diabetes groups. Ages between 40 and 55 years comprised $86.5 \%$ of T2DM patients and $81.2 \%$ of individuals with non-diabetes. For household generation, T2DM had a means of $2.12(\mathrm{SD}=0.48)$ and non-diabetic, $2.04(\mathrm{SD}=0.4)$. However, we found no statistical difference between individuals with T2DM and those without diabetes with respect to the following variables: employment status, marital status, education, school graduation, national health insurance, household region, household head, owner of the house, yearly household income, and subjective health satisfaction.

For women, the average age of individuals with T2DM was 46.1 years, and that of those without diabetes was 45.6 years. The comparison with non-diabetes groups showed that the T2DM group participants were more likely to live in urban areas and to be in multigenerational households $(p<0.01)$ but were less likely to be household heads and recorded a lower subjective health satisfaction $(p<0.05)$. Living in urban areas comprised $57.7 \%$ of the T2DM patients and $41.2 \%$ of the individuals with non-diabetes. For household generation, T2DM had a means of $2.13(\mathrm{SD}=0.51)$ and non-diabetes, $2.0(\mathrm{SD}=0.4)$. Household head represented $3.7 \%$ of $\mathrm{T} 2 \mathrm{DM}$ patients and $8.7 \%$ of non-diabetes individuals. Respondents between normal and good in subjective health satisfaction comprised $80.9 \%$ of T2DM patients and $87.1 \%$ of non-diabetes individuals. However, no statistical difference was found between the T2DM group and non-diabetes groups with respect to the following: employment status, age, marital status, education, school graduation, national health insurance, owner of the house, and yearly household income. 
Table 2. Descriptive statistics by gender with and without type 2 diabetes mellitus (T2DM) in the Korea Health Panel Study, $2013-2015$.

\begin{tabular}{|c|c|c|c|c|c|c|c|c|c|c|}
\hline \multirow{3}{*}{ Variables } & \multicolumn{4}{|c|}{$\operatorname{Men}(N=5466)$} & \multicolumn{6}{|c|}{ Women $(N=5750)$} \\
\hline & \multirow{2}{*}{\multicolumn{2}{|c|}{$\begin{array}{c}\text { T2DM } \\
(N=207)\end{array}$}} & \multicolumn{2}{|c|}{$\begin{array}{l}\text { Non-Diabetic } \\
(N=5259)\end{array}$} & & \multicolumn{2}{|c|}{$\begin{array}{c}\text { T2DM } \\
(N=163)\end{array}$} & \multicolumn{2}{|c|}{$\begin{array}{c}\text { Non-Diabetic } \\
(N=5587)\end{array}$} & \\
\hline & & & \multicolumn{2}{|c|}{$n \%$} & $p$ & \multicolumn{2}{|c|}{$n \%$} & \multicolumn{2}{|c|}{$n \%$} & $p$ \\
\hline \multicolumn{11}{|l|}{ Employment status } \\
\hline Employed & 195 & 94.2 & 4952 & 94.2 & & 127 & 77.9 & 4492 & 80.4 & \\
\hline Unemployed & 12 & 5.8 & 307 & 5.8 & & 36 & 22.1 & 1095 & 19.6 & \\
\hline Mean $\pm(S D)$ & \multicolumn{2}{|c|}{$0.942 \pm(0.234)$} & \multicolumn{2}{|c|}{$0.941 \pm(0.234)$} & 0.981 & \multicolumn{2}{|c|}{$0.779 \pm(0.416)$} & \multicolumn{2}{|c|}{$0.804 \pm(0.396)$} & 0.431 \\
\hline \multicolumn{11}{|l|}{ Age } \\
\hline 30-39 years & 28 & 13.5 & 993 & 18.9 & & 25 & 15.3 & 1129 & 20.2 & \\
\hline $40-49$ years & 97 & 46.9 & 2538 & 48.3 & & 84 & 51.5 & 2549 & 45.6 & \\
\hline $50-55$ years & 82 & 39.6 & 1728 & 32.9 & & 54 & 33.1 & 1909 & 34.2 & \\
\hline Mean $\pm(\mathrm{SD})$ & \multicolumn{2}{|c|}{$46.570 \pm(6.260)$} & \multicolumn{2}{|c|}{$45.551 \pm(6.733)$} & $<0.05$ & \multicolumn{2}{|c|}{$46.055 \pm(6.495)$} & \multicolumn{2}{|c|}{$45.635 \pm(6.782)$} & 0.436 \\
\hline \multicolumn{11}{|l|}{ Marital status } \\
\hline Married & 157 & 75.9 & 4036 & 76.7 & & 138 & 84.7 & 4617 & 82.6 & \\
\hline Divorced/widowed/separated & 50 & 24.2 & 1223 & 23.3 & & 25 & 15.3 & 970 & 17.4 & \\
\hline Mean $\pm(\mathrm{SD})$ & \multicolumn{2}{|c|}{$0.758 \pm(0.429)$} & \multicolumn{2}{|c|}{$0.767 \pm(0.422)$} & 0.764 & \multicolumn{2}{|c|}{$0.846 \pm(0.361)$} & \multicolumn{2}{|c|}{$0.826 \pm(0.378)$} & 0.501 \\
\hline \multicolumn{11}{|l|}{ Education } \\
\hline No formal education & 2 & 0.9 & 6 & 0.1 & & 3 & 1.8 & 22 & 0.4 & \\
\hline Elementary school & 4 & 1.9 & 83 & 1.6 & & 9 & 5.5 & 255 & 4.6 & \\
\hline Middle-high school & 93 & 44.9 & 2366 & 44.9 & & 92 & 56.4 & 3260 & 58.4 & \\
\hline $2-4$ years of college & 104 & 50.2 & 2501 & 47.6 & & 54 & 33.1 & 1891 & 33.9 & \\
\hline Graduate school & 4 & 1.9 & 303 & 5.8 & & 5 & 3.1 & 159 & 2.9 & \\
\hline Mean $\pm(S D)$ & \multicolumn{2}{|c|}{$3.502 \pm(0.622)$} & \multicolumn{2}{|c|}{$3.572 \pm(0.631)$} & 0.116 & 3.300 & $(0.703)$ & 3.341 & $(0.629)$ & 0.412 \\
\hline School graduation & & & & & & & & & & \\
\hline Yes & 198 & 96.6 & 5021 & 95.6 & & 153 & 95.6 & 5390 & 96.9 & \\
\hline No & 7 & 3.4 & 232 & 4.4 & & 7 & 4.4 & 175 & 3.1 & \\
\hline Mean $\pm(\mathrm{SD})$ & 0.965 & $0.182)$ & 0.955 & $0.205)$ & 0.492 & 0.956 & $(0.205)$ & 0.968 & $(0.174)$ & 0.382 \\
\hline National health insurance & & & & & & & & & & \\
\hline Health insurance & 202 & 97.6 & 5127 & 97.5 & & 158 & 96.9 & 5354 & 95.8 & \\
\hline Medical aids & 5 & 2.4 & 132 & 2.5 & & 5 & 3.1 & 233 & 4.2 & \\
\hline Mean $\pm(S D)$ & 0.975 & $0.153)$ & 0.974 & $0.156)$ & 0.932 & 0.969 & $(0.172)$ & 0.958 & (0.199) & 0.486 \\
\hline Household region & & & & & & & & & & \\
\hline
\end{tabular}


Table 2. Cont

\begin{tabular}{|c|c|c|c|c|c|c|c|c|c|}
\hline \multirow{3}{*}{ Variables } & \multicolumn{3}{|c|}{ Men $(N=5466)$} & \multicolumn{6}{|c|}{ Women $(N=5750)$} \\
\hline & \multirow{2}{*}{$\begin{array}{c}\text { T2DM } \\
(N=207)\end{array}$} & \multirow{2}{*}{\multicolumn{2}{|c|}{$\begin{array}{c}\text { Non-Diabetic } \\
(N=5259)\end{array}$}} & & \multirow{2}{*}{\multicolumn{2}{|c|}{$\begin{array}{c}\text { T2DM } \\
(N=163) \\
n \%\end{array}$}} & \multicolumn{2}{|c|}{$\begin{array}{l}\text { Non-Diabetic } \\
(N=5587)\end{array}$} & \multirow[b]{2}{*}{$p$} \\
\hline & & & & $p$ & & & & & \\
\hline Urban & 46.9 & 2230 & 42.4 & & 94 & 57.7 & 2302 & 41.2 & \\
\hline \multirow[b]{2}{*}{ Mean $\pm(\mathrm{SD})$} & $110 \quad 53.1$ & 3029 & 57.6 & & 69 & 42.3 & 3285 & 58.8 & \\
\hline & $0.468 \pm(0.500)$ & \multicolumn{2}{|c|}{$0.424 \pm(0.494)$} & 0.204 & \multicolumn{2}{|c|}{$0.576 \pm(0.495)$} & \multicolumn{2}{|c|}{$0.412 \pm(0.492)$} & $<0.01$ \\
\hline \multicolumn{10}{|l|}{ Household generation } \\
\hline Mean $\pm(S D)$ & $2.120 \pm(0.482)$ & \multicolumn{2}{|c|}{$2.038 \pm(0.399)$} & $<0.01$ & \multicolumn{2}{|c|}{$2.128 \pm(0.510)$} & \multicolumn{2}{|c|}{$1.995 \pm(0.444)$} & $<0.01$ \\
\hline \multicolumn{10}{|l|}{ Household head } \\
\hline Yes & 78.3 & 4285 & 81.5 & & 6 & 3.7 & 484 & 8.7 & \\
\hline No & $45 \quad 21.7$ & 974 & 18.5 & & 157 & 96.3 & 5103 & 91.3 & \\
\hline Mean $\pm(S D)$ & $0.782 \pm(0.413)$ & \multicolumn{2}{|c|}{$0.814 \pm(0.388)$} & 0.244 & \multicolumn{2}{|c|}{$0.036 \pm(0.188)$} & \multicolumn{2}{|c|}{$0.086 \pm(0.281)$} & $<0.05$ \\
\hline \multicolumn{10}{|l|}{ Owner of the house } \\
\hline Yes & 64.7 & 3607 & 68.6 & & 105 & 64.4 & 3833 & 68.6 & \\
\hline No & 35.3 & 1652 & 31.4 & & 58 & 35.6 & 1754 & 31.4 & \\
\hline Mean $\pm(S D)$ & $0.647 \pm(0.478)$ & \multicolumn{2}{|c|}{$0.685 \pm(0.464)$} & 0.242 & \multicolumn{2}{|c|}{$0.644 \pm(0.480)$} & \multicolumn{2}{|c|}{$0.686 \pm(0.464)$} & 0.257 \\
\hline \multicolumn{10}{|l|}{ Yearly household income } \\
\hline Mean $\pm(S D)$ & $5650.908 \pm(2785.4)$ & \multicolumn{2}{|c|}{$5542.178 \pm(4238.2)$} & 0.714 & 5860.57 & $=(2998.6)$ & 5629.30 & (3513.1) & 0.406 \\
\hline Subjective health satisfaction & & & & & & & & & \\
\hline Normal-good & 89.4 & 4380 & 90.8 & & 127 & 80.9 & 4765 & 87.1 & \\
\hline Bad & $20 \quad 10.6$ & 446 & 9.2 & & 30 & 19.1 & 703 & 12.9 & \\
\hline Mean $\pm(S D)$ & $0.894 \pm(0.308)$ & 0.907 & $0.289)$ & 0.534 & 0.808 & $(0.394)$ & 0.871 & $.334)$ & $<0.05$ \\
\hline Sibling diabetes & & & & & & & & & \\
\hline Yes & 4.8 & & & & 4 & 6.2 & & & \\
\hline No & $197 \quad 95.2$ & & & & 61 & 93.9 & & & \\
\hline Mean $\pm(S D)$ & $0.048 \pm(0.214)$ & & & & 0.061 & $(0.242)$ & & & \\
\hline
\end{tabular}


Table 3 presents the effects of T2DM on employment status by gender using probit regression and 2SLS regression. Model I did not reveal significant impacts of T2DM on employment status among men, whereas according to Model II there was a significant positive impact of T2DM on employment decisions $(p<0.05)$. Model II also showed that school graduation, national health insurance, household generation, household head, owner of the house, yearly household income, and subjective health satisfaction had significant positive effects, whereas age had significant negative effects on the developing T2DM and employment $(p<0.01)$. Thus, men with T2DM were significantly more likely to be employed than men without diabetes, with an estimated increment in employment probability of $25.3 \%$.

Table 3. Effect of T2DM on employment status by gender using probit regression and two-stage least squares(2SLS) regression.

\begin{tabular}{|c|c|c|c|c|c|c|c|c|}
\hline \multirow{3}{*}{ Variables } & \multicolumn{4}{|c|}{ Men } & \multicolumn{4}{|c|}{ Women } \\
\hline & \multicolumn{2}{|c|}{ Model I } & \multicolumn{2}{|l|}{ Model II } & \multicolumn{2}{|c|}{ Model I } & \multicolumn{2}{|l|}{ Model II } \\
\hline & Coef. $(z)$ & $p$ & Coef. $(z)$ & $p$ & Coef. $(z)$ & $p$ & Coef. $(z)$ & $p$ \\
\hline T2DM & $0.164(0.61)$ & 0.544 & $0.253(2.04)$ & $<0.05$ & $-0.086(-0.38)$ & 0.705 & $-0.519(-2.22)$ & $<0.05$ \\
\hline Age & $-0.022(-2.46)$ & $<0.05$ & $-0.003(-3.92)$ & $<0.01$ & $0.049(6.73)$ & $<0.01$ & $0.009(3.59)$ & $<0.01$ \\
\hline Marital status & $0.109(0.62)$ & 0.535 & $0.014(1.04)$ & 0.298 & $-1.160(-7.45)$ & $<0.01$ & $-0.141(-2.62)$ & $<0.01$ \\
\hline Education & $0.002(0.03)$ & 0.979 & $0.005(0.74)$ & 0.460 & $-0.067(-0.93)$ & 0.353 & $-0.002(-0.07)$ & 0.944 \\
\hline School graduation & $0.305(1.65)$ & $<0.1$ & $0.066(3.73)$ & $<0.01$ & $-0.385(-1.78)$ & $<0.1$ & $-0.206(-2.56)$ & $<0.01$ \\
\hline National health insurance & $0.749(3.23)$ & $<0.01$ & $0.099(4.28)$ & $<0.01$ & $1.251(6.41)$ & $<0.01$ & $0.212(2.96)$ & $<0.01$ \\
\hline Household region & $-0.079(-0.78)$ & 0.435 & $-0.005(-0.70)$ & 0.481 & $-0.463(-5.73)$ & $<0.01$ & $0.005(0.16)$ & 0.869 \\
\hline Household generation & $0.356(2.66)$ & $<0.01$ & $0.035(3.73)$ & $<0.01$ & $0.115(1.29)$ & 0.197 & $0.006(0.21)$ & 0.836 \\
\hline Household head & $2.017(8.23)$ & $<0.01$ & $0.230(14.62)$ & $<0.01$ & $-0.134(-0.66)$ & 0.508 & $0.015(0.21)$ & 0.832 \\
\hline Owner of the house & $0.245(2.11)$ & $<0.05$ & $0.023(2.94)$ & $<0.01$ & $-0.267(-3.15)$ & $<0.01$ & $-0.028(-0.95)$ & 0.340 \\
\hline Yearly household income & $0.00009(4.96)$ & $<0.01$ & $2.44 \times 10^{-6}(3.37)$ & $<0.01$ & $0.00002(2.13)$ & $<0.05$ & $1.89 \times 10^{-6}(0.50)$ & 0.616 \\
\hline $\begin{array}{l}\text { Subjective health } \\
\text { satisfaction }\end{array}$ & $0.628(4.90)$ & $<0.01$ & $0.056(5.59)$ & $<0.01$ & $0.129(1.34)$ & 0.181 & $0.048(1.45)$ & 0.148 \\
\hline
\end{tabular}

Note: Model I uses probit regression and Model II uses 2SLS regression.

For women, Model I showed that T2DM had no significant impact on employment decisions, whilst Model II showed a significant negative impact of T2DM on employment status $(p<0.05)$. Model II also identified marital status and school graduation as negative factors, whereas age and national health insurance were identified as positive drivers in the T2DM and employment relationship $(p<0.01)$. Therefore, women with T2DM were significantly less likely to be employed than women without diabetes, with an estimated reduction in employment probability of $51.9 \%$.

\section{Discussion}

Previous studies have analyzed the impact of diabetes mellitus on labor market participation by men and women, but gender difference between T2DM and employment has not been the focus. Thus, we examined gender differences between T2DM and employment status using the Korea Health Panel Study. We estimated the generalized two-stage least squares (2SLS), controlling for unobserved factors of T2DM and used an instrumental variable (IV), such as a sibling with diabetes. Our finding demonstrated the interaction effects between T2DM and employment. T2DM had a statistically significant and negative effect on employment in women only.

This finding is consistent with previous studies. Gender gaps in employment have been attributed to women having to care for the socially weak population, including childbearing and childrearing. Meanwhile, the employment status of men is less affected, owing to the influence of labor market productivity on the probability of men's labor force $[12,26]$. Indeed, studies have consistently indicated that women were more involved in family roles and had higher expectations of those roles than men $[13,14]$. Similar to the IV methodology, our analyses presented the impact of diabetes on employment status, estimated after controlling for the existence of endogeneity using a diabetic sibling as an IV. Latif [18] used family history of diabetes as an IV and found that diabetes had a significant negative impact on employment in women. Minor [19] analyzed the effects of T2DM separately 
and used individuals' biological mother as an IV; the results showed that women with T2DM were significantly less likely to be employed at almost $50 \%$ as compared with healthy individuals.

These findings have significant implications for policy and practice. Public health policies to prevent chronic diseases must do more to protect the employment of patients with T2DM. Particularly, women seem to be vulnerable to leaving employment owing to their larger day-to-day household responsibilities, including childcare and housework. Moreover, understanding gender differences in T2DM can be useful for policymakers who are tasked with reducing the gender gap in employment and researchers who want to analyze deeply these decision factors. Korea should consider developing tailored and evidence-based prevention and disease management programs for diabetic patients using gender-specific remedies [28-30].

Meanwhile, our study has several limitations. First, insufficient IVs could lead to inconsistent results on diabetes. The number of IVs used in the estimation must be equal to or greater than the number of endogenous explanatory variables [21]. Further research using more IVs could be driven by the accurate identification of samples. Second, our data did not include potential discrimination for T2DM in the workplace. Owing to the nature of our data, we could not identify employment patterns. Indeed, previous studies have shown that diabetes per se is not a source of stigma $[9,31]$. Third, the nature of employment was not considered in our study. In short, having a blue-or white-collar job and being fully or partially employed could be dependent on gender. These factors need to be considered in further studies.

Nevertheless, our study has the following main strengths. We used the KHPS and analyzed nationally representative dataset. Our method provided the opportunity to account for time-invariant unobserved characteristics. We also distinguished T2DM using theICD-10 diagnosis code and excluded respondents with missing values or a combination of co-morbidities (e.g., hypertension, hyperlipidaemia, arthropathy, and ischemic heart disease). Thus, our study could analyze purely the impact of T2DM using family history of diabetes as an IV, by controlling for unobserved factors, such as personal traits, motivation, and healthy lifestyle, with respect to employment status.

\section{Conclusions}

This study explored the relationship between T2DM and employment status in terms of gender differences by using a nationally representative dataset (KHPS Version 1.4). Our results showed that the interaction effects between T2DM and employment. T2DM had a statistically significant and negative effect on employment of women only. Women, who are in an inferior position in the labor market, are the main provider of childcare and domestic work. The negative influence on T2DM is more marked for women as compared with men. To our knowledge, this study is the first to report the impact of employment decision on T2DM by gender in Korea. Exposing gender bias in employment suggests that healthcare policies and disease management programs for diabetic patients should adopt gender-specific remedies. Further research needs to investigate the factors underlying the persistent gender differences in performing family responsibilities.

Author Contributions: Conceptualization, W.-Y.L. and S.S.L.; Formal analysis, J.-H.K. and Y.T.K.; Project administration, W.-Y.L. and S.S.L.; Writing-original draft, J.-H.K.; Writing-review and editing, Y.T.K. and Y.-P.H. All authors have read and agreed to the published version of the manuscript.

Funding: This research received no external funding.

Conflicts of Interest: The authors declare no conflict of interest. 


\section{References}

1. World Health Organization. Global Report on Diabetes. 2016. Available online: https://www.who.int/ diabetes/global-report/en (accessed on 30 December 2019).

2. Center for Disease Control and Prevention. National Diabetes Statistics Report. 2017. Available online: https://www.cdc.gov/features/diabetes-statistic-report/index.html (accessed on 30 December 2019).

3. Korean Statistical Information Service. Cause of Death Statistics. KOSIS. 2019. Available online: http://kosis.kr (accessed on 30 December 2019).

4. Korean Center for Disease Control and Prevention. Korea Health Statistics: Korea National Health and Nutrition Examination Survey (KNHANES VII-2). 2017. Available online: http://knhanes.cdc.go.kr (accessed on 30 December 2019). (In Korean)

5. Alberti, K.G.; Zimmet, P.Z. Definition, diagnosis and classification of diabetes mellitus and its complications. Part 1: Diagnosis and classification of diabetes mellitus provisional report of a WHO consultation. Diabet Med. 1998, 15, 539-553. [CrossRef]

6. Cho, N.H. Diabetes burden and prevention in Korea and the Western Pacific Region. Diabetes Res. Clin. Pract. 2014, 106, S282-S287. [CrossRef]

7. Pedron, S.; Emmert-Fees, K.; Laxy, M.; Schwettmann, L. The impact of diabetes on labour market participation: A systematic review of results and methods. BMC Public Health 2019, 19, 25. [CrossRef] [PubMed]

8. Passey, M.E.; Shrestha, R.N.; Bertram, M.Y.; Schofield, D.J.; Vos, T.; Callander, E.J.; Percival, R.; Kelly, S.J. The impact of diabetes prevention on labour force participation and income of older Australians: An economic study. BMC Public Health 2012, 12, 16. [CrossRef]

9. Kraut, A.; Walld, R.; Tate, R.; Mustard, C. Impact of diabetes on employment and income in Manitoba. Can. Diabetes Care 2001, 24, 64-68. [CrossRef]

10. Rumball-Smith, J.; Barthold, D.; Nandi, A.; Heymann, J. Diabetes associated with early labor-force exit: A comparison of sixteen high-income countries. Health Aff. 2014, 33, 110-115. [CrossRef]

11. Benach, J.; Muntaner, C.; Santana, V. Employment Conditions and Health Inequalities. World Health Organization. 2007. Available online: https:/www.who.int/social_determinants/themes/employmentconditions/en (accessed on 30 December 2019).

12. Vives, A.; Gray, N.; González, F.; Molina, A. Gender and Ageing at Work in Chile: Employment, Working Conditions, Work-Life Balance and Health of Men and Women in an Ageing Workforce. Ann. Work Expo. Health 2018, 62, 475-489. [CrossRef]

13. Malmusi, D.; Vives, A.; Benach, J.; Borrell, C. Gender Inequalities in Health: Exploring the Contribution of Living Conditions in the Intersection of Social Class. Glob. Health Action 2014, 7, 23189. [CrossRef]

14. Esteban-Gonzalo, S.; Aparicio, M.; Estaban-Gonzalo, L. Employment Status, Gender and Health in Spanish Women. Women Health 2018, 58, 744-758. [CrossRef]

15. Petrongolo, B. The gender gap in employment and wages. Nat. Hum. Behav. 2019, 3, 316-318. [CrossRef]

16. Noh, J.W.; Kim, K.B.; Park, J.; Hong, J.; Kwon, Y.D. Relationship between the number of family members and stress by gender: Cross-sectional analysis of the fifth Korea National Health and Nutrition Examination Survey. PLoS ONE 2017, 12, e0184235. [CrossRef]

17. Brown, H.S., 3rd; Pagán, J.A.; Bastida, E. The impact of diabetes on employment: Genetic IVs in a bivariate probit. Health Econ. 2005, 14, 537-544. [CrossRef]

18. Latif, E. The impact of diabetes on employment in Canada. Health Econ. 2009, 18, 577-589. [CrossRef] [PubMed]

19. Minor, T. The effect of diabetes on female labor force Decemberisions: New evidence from the National Health Interview Survey. Health Econ. 2011, 20, 1468-1486. [CrossRef] [PubMed]

20. The Korea Health Panel Study Data. 2013-2015. Available online: http://www.khp.re.kr (accessed on 30 December 2019).

21. Wooldridge, J.M. Econometric Analysis of Cross Section and Panel Data; MIT Press: Cambridge, MA, USA, 2001; pp. 247-298.

22. National Health Insurance Service. Available online: http://www.nhis.or.kr (accessed on 30 December 2019).

23. Johnsen, T.L.; Eriksen, H.R.; Indahl, A.; Tveito, T.H. Directive and nondirective social support in the workplace-Is this social support distinction important for subjective health complaints, job satisfaction, and perception of job demands and job control? Scand J. Public Health 2018, 46, 358-367. [CrossRef] 
24. Park, J.; Han, B.; Kim, Y. Association of Job Satisfaction and Security with Subjective Health and Well-Being in Korean Employees. J. Occup. Environ. Med. 2018, 60, e525-e532. [CrossRef] [PubMed]

25. Seuring, T.; Goryakin, Y.; Suhrcke, M. The impact of diabetes on employment in Mexico. Econ. Hum. Biol. 2015, 18, 85-100. [CrossRef]

26. Minor, T. An investigation into the effect of type I and type II diabetes duration on employment and wages. Econ. Hum. Biol. 2013, 11, 534-544. [CrossRef]

27. Greene, W.H. Econometric Analysis, 6th ed.; Prentice Hall: Upper Saddle River, NJ, USA, 2008; pp. 314-331.

28. Brown, H.S., III; Perez, A.; Yarnell, L.M.; Pagan, J.A.; Hanis, C.L.; Fischer-Hoch, S.P.; McCormock, J.B. Diabetes and employment productivity: Does diabetes management matter? Am. J. Manag. Care. 2011, 17, 569-576.

29. American Diabetes Association; Anderson, J.E.; Greene, M.A.; Griffin, J.W., Jr.; Kohrman, D.B.; Lorber, D.; Saudek, C.D.; Schatz, D.; Siminerio, L. Diabetes and employment. Diabetes Care 2014, 37, S112-S117.

30. Dusheiko, M.; Gravelle, H.; Martin, S.; Rice, N.; Smith, P.C. Does better disease management in primary care reduce hospital costs? Evidence from English primary care. J. Health Econ. 2011, 30, 919-932. [CrossRef] [PubMed]

31. Olesen, K.; Cleal, B.; Willaing, I. Discrimination and stigma among people with type 2 diabetes in the workplace: Prejudice against illness or obesity? Public Health 2019, 180, 100-101. [CrossRef] [PubMed]

(C) 2020 by the authors. Licensee MDPI, Basel, Switzerland. This article is an open access article distributed under the terms and conditions of the Creative Commons Attribution (CC BY) license (http://creativecommons.org/licenses/by/4.0/). 